Review

\title{
Glypican-3: A New Target for Diagnosis and Treatment of Hepatocellular Carcinoma
}

\author{
Meng Guo ${ }^{1,2^{*}}$, Hailing Zhang $3^{*}$, Jianming Zheng ${ }^{\llbracket}$, Yangfang Liu $4^{\bowtie}$ \\ 1. National Key Laboratory of Medical Immunology \&Institute of Immunology, Second Military Medical University, Shanghai, China \\ 2. Institute of Organ Transplantation, Changzheng Hospital, Second Military Medical University, Shanghai, China \\ 3. Department of Neurology, Changhai Hospital, Second Military Medical University, Shanghai, China \\ 4. Department of Pathology ,Changhai Hospital, Second Military Medical University, Shanghai, China \\ *Meng Guo and Hailing Zhang are co-first authors. \\ $\triangle$ Corresponding authors: Yanfang Liu, Department of pathology, Changhai Hospital, Second Military Medical University, Shanghai, China; Tel: \\ +86-21-31162262; Email: Liuyanfang00215@163.com and Jianming Zheng, Department of pathology, Changhai Hospital, Second Military Medical University, \\ Shanghai, China; Shanghai, China; Tel: +86-21-31162257; Email: Jmzheng1962@smmu.edu.cn
}

() The author(s). This is an open access article distributed under the terms of the Creative Commons Attribution License (https://creativecommons.org/licenses/by/4.0/). See http://ivyspring.com/terms for full terms and conditions.

Received: 2019.09.04; Accepted: 2020.01.04; Published: 2020.02.03

\begin{abstract}
Liver cancer is the second leading cause of cancer-related deaths worldwide, and hepatocellular carcinoma is the most common type. The pathogenesis of hepatocellular carcinoma is concealed, its progress is rapid, its prognosis is poor, and the mortality rate is high. Therefore, novel molecular targets for hepatocellular carcinoma early diagnosis and development of targeted therapy are critically needed. Glypican-3, a cell-surface glycoproteins in which heparan sulfate glycosaminoglycan chains are covalently linked to a protein core, is overexpressed in HCC tissues but not in the healthy adult liver. Thus, Glypican-3 is becoming a promising candidate for liver cancer diagnosis and immunotherapy. Up to now, Glypican-3 has been a reliable immunohistochemical marker for hepatocellular carcinoma diagnosis, and soluble Glypican-3 in serum has becoming a promising marker for liquid biopsy. Moreover, various immunotherapies targeting Glypican-3 have been developed, including Glypican-3 vaccines, antiGlypican-3 immunotoxin and chimeric-antigen-receptor modified cells. In this review, we summarize and analyze the structure and physicochemical properties of Glypican-3 molecules, then review their biological functions and applications in clinical diagnosis, and explore the diagnosis and treatment strategies based on Glypican-3.
\end{abstract}

Key words: hepatocellular carcinoma, Glypican-3, immunotherapy, diagnostics

\section{Introduction}

Hepatocellular carcinoma (HCC) is the second leading cause of cancer deaths in the world [1]. The HCC incidence cases and number of deaths in China account for more than $50 \%$ of the total all over the world, while the mortality rate is in the third place [2]. Although the HCC treatment protocols tend to be diversified and combined, it is difficult to achieve further improvement in the long-term survival of HCC patients in the last 10 years. Liver resection or transplantation is the first choice for HCC treatment so far. However, the 1-year recurrent rate is close to $40 \%$ after surgical operation, and the 5-year recurrent rate is as high as $50 \%$ to $70 \%$ [3]. Although 5-year disease-free survival rate of patients receiving liver transplantation could reach $60 \% \sim 80 \%, 10 \% \sim 20 \%$ of recipients would suffer tumor recurrence after liver transplantation [4]. Many studies indicate those tumors have begun to spread circulating tumor cells (CTC) to the bloodstream with a diameter of only $0.5 \mathrm{~cm}-1 \mathrm{~cm}$ (limit of imaging examination), even forming tiny metastases in distal organs, which become high-risk factors for recurrence and distant metastasis after radical resection in HCC patients [4]. Therefore, the search for HCC-specific surface molecules has important clinical significance and application value for the detection, diagnosis and targeted therapy of liver cancer. 
Compared with normal hepatocytes, there are many surface molecules high expressed on the surface of HCC cells, such as glypican-3 (GPC3) [5], asialoglycoprotein receptor (ASGP-R) [6], transferrin receptor (TfR) [7], AF20 antigen [8], somatostatin receptor (SSTR) [9], lysosome-associated protein transmembrane $4 \beta$ (LAPTM4B) [10]. Among these surface molecules, ASGP-R, TfR, AF20 antigen, SSTR and LAPTM4B are potential therapeutic targets for HCC, but unsuitable for HCC diagnosis. Compared with the those molecules, GPC3 is rarely expressed in adult and not expressed in pathological liver cells such as hepatitis, cirrhosis, and fatty liver. Also, GPC3 located on the surface of liver cells, so that antibody-based drugs or CAR-T/NK can be designed for specific killing of tumor cells with low risk of off-tumor effect.All these features determine GPC3 is the best diagnostic and therapeutic target for liver cancer.

In the past decade, GPC3, which specifically expressed on the surface of HCC cells, has become a new star molecule with high correlation with the occurrence and development of HCC. Not only GPC3 can be used as a biomarker for diagnosis, but also as an important target for immunotherapy of HCC.

Glypican (GPC) belongs to the heparan sulfate proteoglycans family with similar structures, including: a $60-70 \mathrm{kD}$ core protein, which is linked to the surface of the cell membrane by a glycosylphosphatidylinositol anchor (GPI), and the carboxy terminus is modified with a heparan sulfate side chain [11]. Currently, there are six members of the GPC family have been identified in the genome of mammals: GPC1 to GPC6 [12, 13]. All GPCs proteins are highly expressed during embryonic development [14-16]: GPC1 is expressed in bone, bone marrow, muscle, epithelium and kidney. GPC2 is specifically expressed in nervous system. GPC3 and GPC6 are widely expressed on various cell surfaces of embryos. GPC4 is expressed in brain, kidney and lung. GPC5 is expressed in brain, lung, liver, kidney and limbs. Compared with embryonic phase, the expression pattern of GPCs changes greatly in adults $[15,17,18]$ : GPC1, GPC4 and GPC6 are widely expressed in various tissues; GPC2 is no longer expressed; GPC3 is only expressed in the ovary; GPC5 is specifically expressed in the brain.

The expression pattern of GPCs suggests that these molecules play an important role in the growth and morphogenesis during individual development. Recent studies have also shown that GPCs are highly correlated with tumor development. Aikawa, $\mathrm{T}$ et al. found that GPC1 is associated with pancreatic cancer growth, migration and angiogenesis [19]; in addition, Whipple, CA et al. revealed that in KRAS mutation-induced pancreatic cancer, GPC1 is the key molecule for tumor growth and angiogenesis [20]; exosomes containing GPC1 in peripheral blood can be used as biomarkers for the diagnosis of pancreatic cancer. GPC1 is also up-regulated in breast cancer [21], esophageal squamous cell carcinoma [22], and glioma [23], which suggests a poor prognosis. GPC2 is mainly expressed in the tumors of nervous system, such as neuroblastoma. Yet GPC2 expression in other types of tumors has not been reported. Unfortunately, GPC4, GPC5 and GPC6 are relatively poorly studied. Some studies have shown that GPC4 is highly expressed in pancreatic cancer [24], GPC5 is down-regulated in non-small cell lung cancer [25], and GPC6 is up-regulated in ovarian cancer and positively correlated with prognosis [26].

GPC3 is a star molecule in the GPCs family. Recently, the diagnostic value of GPC3 in HCC has been gradually recognized: GPC3 is specifically expressed in liver cancer tissues, and presents as soluble GPC3 (sGPC3) in peripheral blood of HCC patients, while its expression is not detected in the liver tissues of healthy adults, or pathological samples of fatty liver, or liver with cirrhosis, hepatitis, or injury, suggesting that GPC3 is a more reliable tumor marker than alpha-fetoprotein (AFP). In addition, GPC3 is rarely expressed in other normal tissues of adults, and therefore is suitable for targeted therapy as a tumor antigen $[27,28]$. Hence, in this review, we summarize and analyze the structure and physicochemical properties of GPC3 molecules, then review their biological functions and applications in clinical diagnosis, and explore the diagnosis and treatment strategies based on GPC3.

\section{Sequence, structure and physicochemical properties of GPC3}

The GPC3 gene is located on the long arm of the $X$ chromosome at position 26, and contains 11 exons. The transcript is $2130 \mathrm{bp}$, encoding 580 amino acids, and the molecular weight of the protein is about 70 $\mathrm{kDa}$. The polypeptide contains a Furin restriction enzyme site, and by cleavage of the peptide bond between Arg358 and Cys359, the GPC3 protein is cleaved into two fragments: N-terminal at $40 \mathrm{kD}$ and C-terminal at $30 \mathrm{kD}$; These two subunits can be connected by one or more disulfide bonds, and the $\mathrm{N}$-terminal subunit can be further sheared to form sGPC3 in the peripheral circulation; Heparan sulfate modification occurs at two sites of GPC3: Cys495 and Cys508; Ser560 is anchored to the lipid raft on cell membrane by phosphatidylinositol (Figure 1).

The sequences conservation of GPC3s were analyzed in human (Query_10001), mouse (Query_ 10002), alpaca (Query_10003), camel (Query_10004) 
through the in line tool COBALT [29] (Constraintbased Multiple Alignment Tool, https://www.ncbi. nlm.nih.gov/tools/cobalt). The results indicated that GPC3 is highly conservative in these four species (Figure 2), suggesting that direct expression of GPC3 as an antigen may not achieve a good immune effect, and hapten-carrier protein bioconjugate should be used to immunize the animal, or screening the antibody phage display library to obtain an effective antibody.

The signal peptide sequence of GPC3 was analyzed using the on line tool SignalP 4.1 (http:// www.cbs.dtu.dk/services/SignalP/) [30]. The results showed that the max $\mathrm{C}$ and $\mathrm{Y}$ scores were located at 25th amino acid, 0.848 and 0.862 , respectively, suggesting that the membrane protein signal peptide (Figure 3) consists of the 1-24 amino acids.

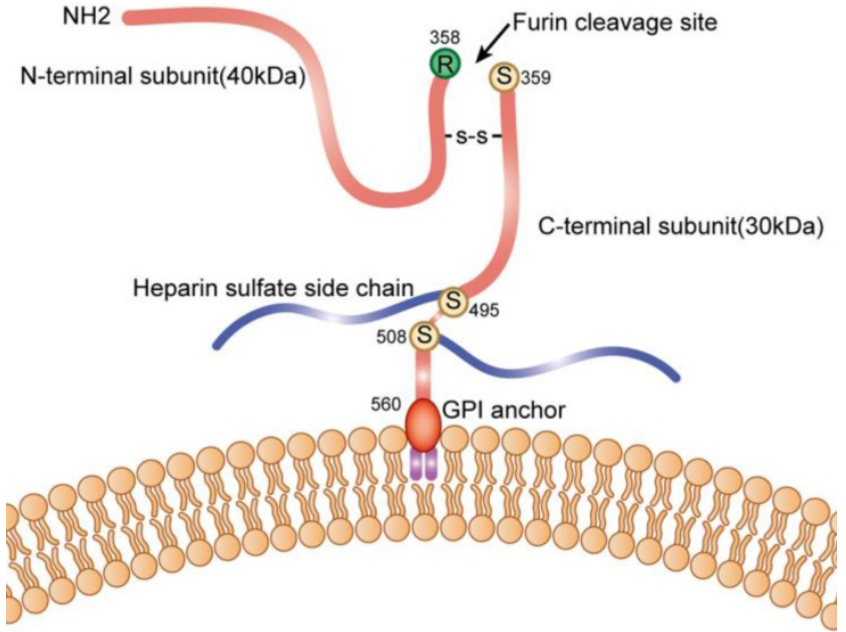

Figure 1. Schematic diagram of GPC3 on the cell membrane.

Human
Mouse
Alpaca
Camel

Query_10001 137 LTPQAFEFVGEFFTDVSL_YILGSD INVDDMVNELFDSLFPVIYTQLINIPGLPDSALD INECLRGARRDLKVFGNFPKLIM 216 Query_10002 136 LTPQAFEFVGEFFTDVSLYILGSDINVDDMVNELFDSLFPVIYTMOMNPG.PESVLDINECLRGARRDLKVFGSFPKLIM 215 Query_10003 161 LTPQAFEFVGEFFTDVSLYILGSDINVDDMVNELFDSLFPVIYTQLMNPGLPESALDINECLRGARRDLKVFGNFPKLIM 240 Query_10004 159 LTPQAFEFVGEFFTDVSLYYLLGDDINWDDMVNELFDSLFPVIYTQLINPGL.PESALDINECLRGARRDLKVFGNFPKLIM 238

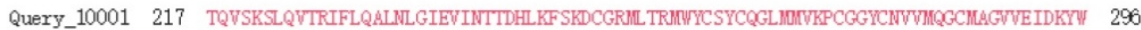

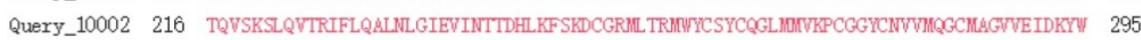
Query_10003 241 TQVSKSLQVTRTFLQALNLGIEVINTTDHLKFSKDCGRMLTRMWYCSYCQGLNOWVKPCGGYCNWIWQGCMAGVVIDKYW 320 Query_10004 239 TQVSKSLQVTRIFLQALNLGIEVINTTDHLKFSKDCGRMLTRMYYCSYCQGLINOVKPCGGYCNWVIMGCMAGVEIDKYW 318

Query_10001 297 REYILSLEELWWGIYRTYDIENVLLGLFSTIHDSIQYVQKNAGKLTTTIGKLCAHSQQRQYRSAYYPEDLFIDKKVLKVA 376 Query_10002 296 REYILSLEELWWGIYYTYDMENVLLGLFTIHDSIQYVQKNGGKL TTTIGKLCAHSQQRQYRSAYYPEDLFDKKILKVA 375 Query_10003 321 REYILSLEELVTGIYYRTYDMENVLLGLFSMIHDSIQYVQKNGGKLTTTVGKLCAHSQQRQYRSAYYPEDLFTDKVLKVA 400 Query_10004 319 REYILSLEELVTGIYRTYDIENVLLGLFTIHDSIQYVQKIVGKLTTTIGRLCAHSQQRQYRSAYYPEDLFDKKVLKVA 398

Query_10001 377 HVEHEETLSSRRRELIQKLKSFISFYSALPGYICSHSPVAENDTLCUNGQEL VERYSQKAARNGMKNDFILLELLKIKGPE 456 Query_10002 376 HVEHEETLSSRRRELIQKLKSFINFYSALPGYICSHSPVAENDTLCWNGQELVERYSQKAARNGMKNRFNLHELKMKKCPE 455 Query_10003 401 HVEHEETLSSRRRELIQKLKSSFISFYSALPGYICSHSPVAENDTLCWNGQELVVRYSQRAARWGMKNRFILHELKIIKGPE 480 Query_10004 399 HVEHEETLSSRRRELIQKLKSFISFYSALPGYICSHSPVAENDTLCWNGQELVERYSQKA.ARNGMKNRFNLHELKMKGPE 478

Query_10001 457 PWSQIIDKLKHINQLLRTMSMPKGRVLDKNLDEEGFESGDCGDDEDECIGGSGDGMIKVKNQLRFLAELAYDLDVDAP 536 Query_10002 456 PVVSQIIDKLKHINQLLRTMSVPKGKVLDKSLDEEGLESGDCGDEDECIGSSGDGMVKVKNQLRFLAELAYLLDVDAP 535 Query_10003 481 PWSQIIDKLKHINQLLRTHSWPKGRVLDKNLDEEGLESGDCGDDEDECIGGSGDGTMKKVKWLRFLAELAYDLDVDDAP 560 Query_10004 479 PVVSQIIDKLKHINQLLRTMSVPKGRVLDKNLDEEGLESGDCGDDEDECIGGSGDGTMKVKNQLRFLAELAYYDLDVDDAP 558

Query_10001 537 GNSQQAT-PKDNEISTFHNLGNHSPLKLLTSMAISWWFFFLVH 580

Query_10002 536 GNKQHGN-QKDNEITTSHSVGMNPSPLKILISVAIYVACFFFLVH 579

Query_10003 561 GSKQHGNHQKDNEITASHNLGMGPSPLKVLTSLAVSVACFFFLVH 605

Figure 2. Conservative analysis of the GPC3 protein sequence. 
Based on the above analyses, the sequence of GPC3 mature protein was analyzed for physicochemical properties using the on line tool ProtParam (https://web.expasy.org/protparam/). The results showed that the GPC3 mature protein contains 579 amino acids, the molecular formula is $\mathrm{C}_{2950} \mathrm{H}_{4609} \mathrm{~N}_{779} \mathrm{O}_{858} \mathrm{~S}_{39}$, and the molecular weight is 65967.09Da, the theoretical isoelectric point is 6.01, indicating that the GPC3 protein is acidic. The leucine is the most abundant amino acid in peptide, accounting for $10.3 \%$ of the total amino acids. The secondary structure was predicted by DNAstar, as shown in Figure 4 . The $\beta$-turn and irregular coils, which are often located on the surface of the protein and which is beneficial to antigen-antibody interaction, are richer in the C-terminal subunit. Therefore, the C-terminal subunit shall be used in designing the antigen to immunize animal.

\section{Biological function of GPC3}

Under normal physiological conditions, GPC3 is widely expressed on the membrane of various embryonic cells, but not on those in adult liver. GPC3 mutation causes simpson golabi behmel syndrome (SGBS) in humans, i.e. macrosomia accompanied by dysplasia of multiple organs and skeletons [31]. Knockout of GPC3 in mice also causes symptoms similar to SGBS, manifested as excessive growth of somatic cells before and after birth [32]. These evidences indicate that GPC3 is involved in the regulation of growth and development of the body.

GPC3 is a membrane protein anchored to the surface of the cell membrane, without an intracellular segment which transmits signals. However, GPC3 is an important component of the extracellular matrix (ECM) [33]. GPC3 could interact with a variety of growth factors, chemokines, and cytokines to form a concentration gradient on the surface of the cell membrane, which promotes these ligands binding to their related receptors. In this sense, GPC 3 acts as an extracellular signal "recruiter" in various signaling pathways, playing a crucial role in maintaining the concentration of extracellular ligands and promoting ligand-receptor interactions. Studies have shown that the loss of GPC3 during development leads to changes in downstream signals such as WNT and Hedgehog [32, 34-37].

\section{WNT signaling pathway}

WNT signaling pathway plays an important role in many pathological and physiological processes, directly regulating embryonic development, cell differentiation, tumorigenesis and metastasis and invasion etc. The WNT signaling pathway is mainly composed of the ligand WNTs protein family, membrane receptor protein, cytoplasmic signal transduction protein and the downstream transcription factor [38]. A total of 18 WNT family members have been identified in humans, including WNT1, WNT2, WNT3, WNT3A, WNT4, and WNT16 etc. Different WNT members can activate different signaling pathways, when WNT1, 2, 3, 3a, and 8 etc. activating their receptors, followed by downstream signal $\beta$-catenin, it is called the canonical WNT signaling pathway (WNT/ $\beta$-catenin pathway). WNT4, 5a, and $5 \mathrm{~b}$ etc. involve in non-canonical WNT signaling pathways, including WNT/ $\mathrm{Ca}^{2+}$ signaling pathway and WNT/PCP signaling pathway [38-40]. Receptors for WNTs include frizzled (FZD) and LDL receptor related protein5/6 (LRP5/6) [41]: the N-terminus of FZD protein carries a cysteine-rich domain consisting of 120 amino acids, and it can bind with high affinity to WNTs [42]; LRP5/6 is a single transmembrane protein consisting of about 1600 amino acids, and its extracellular domain is composed of four tandem $\beta$-propeller domains. It can bind with different WNTs and form a complex with FZD [43]. The membrane complex transmits signals and activates the dishevelled (DSH or Dvl) in the cytoplasm, which in turn mediates canonical or non-canonical activation of the WNT pathway [39] (Figure 5).

GPC3 is an important regulator of WNT signaling pathway in the initial stage. Studies have shown that GPC3 can help the activation of WNT signaling by promoting the formation of membrane surface complexes in liver cancer [44]. Both the GPC3 protein and the heparan sulfate side chain can interact with FZD and WNTs [45, 46], and play as a "signal recruiter" in the initial activation-stage of the WNT signaling; in addition, the presence of GPC3 can further stabilize the binding of WNTs to FZD, thereby positively regulate WNTs downstream signal transduction [46] (Figure 5).

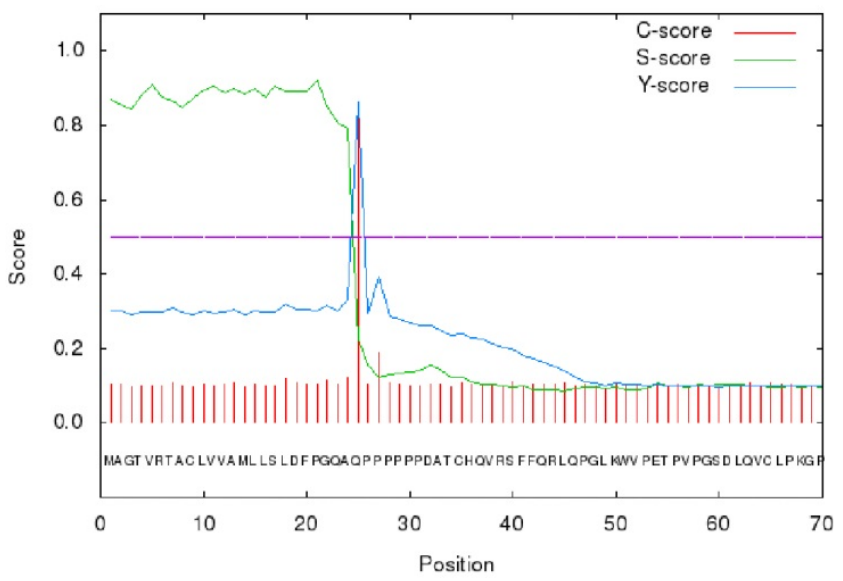

Figure 3. SignalP 4.1 analysis of GPC3 signal peptide. 


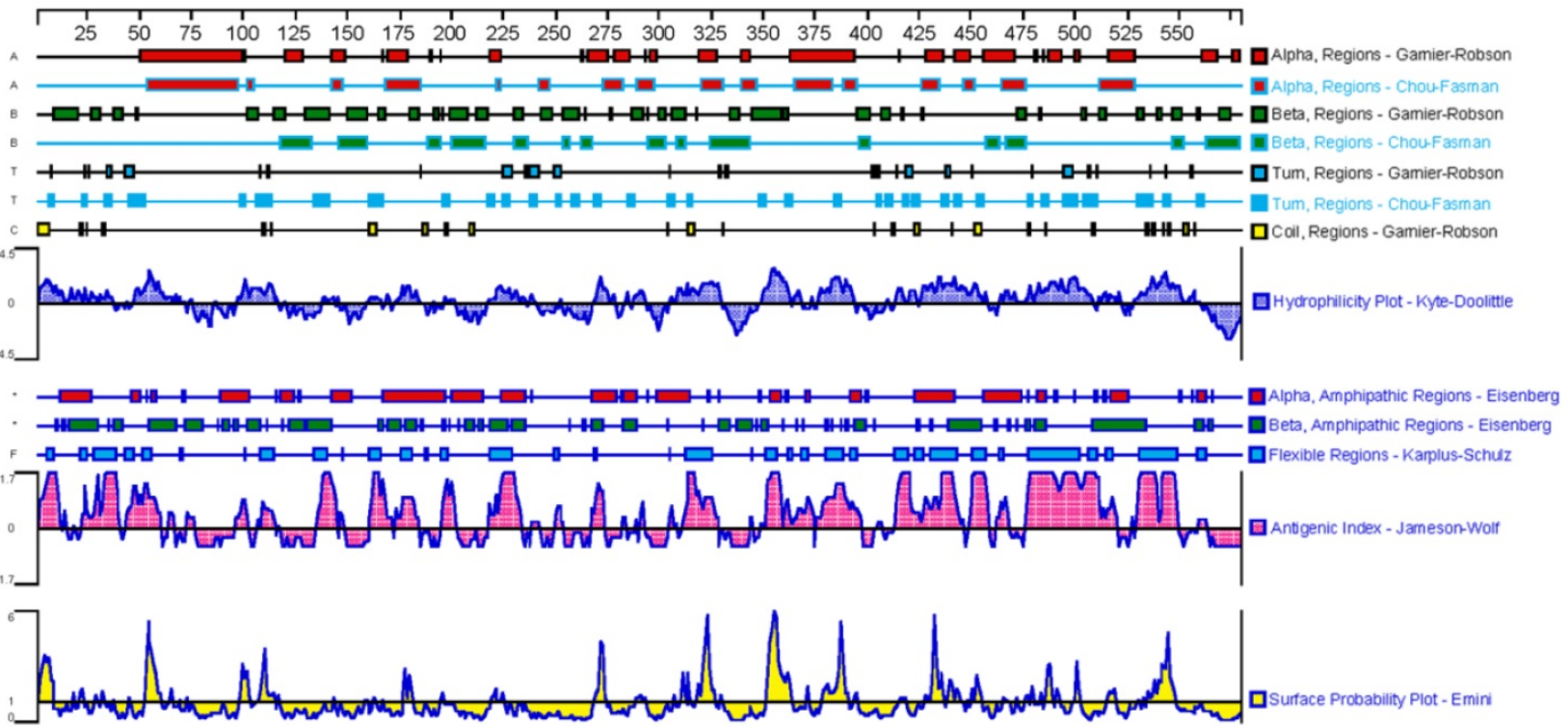

Figure 4. Analysis of the GPC3 secondary structure.

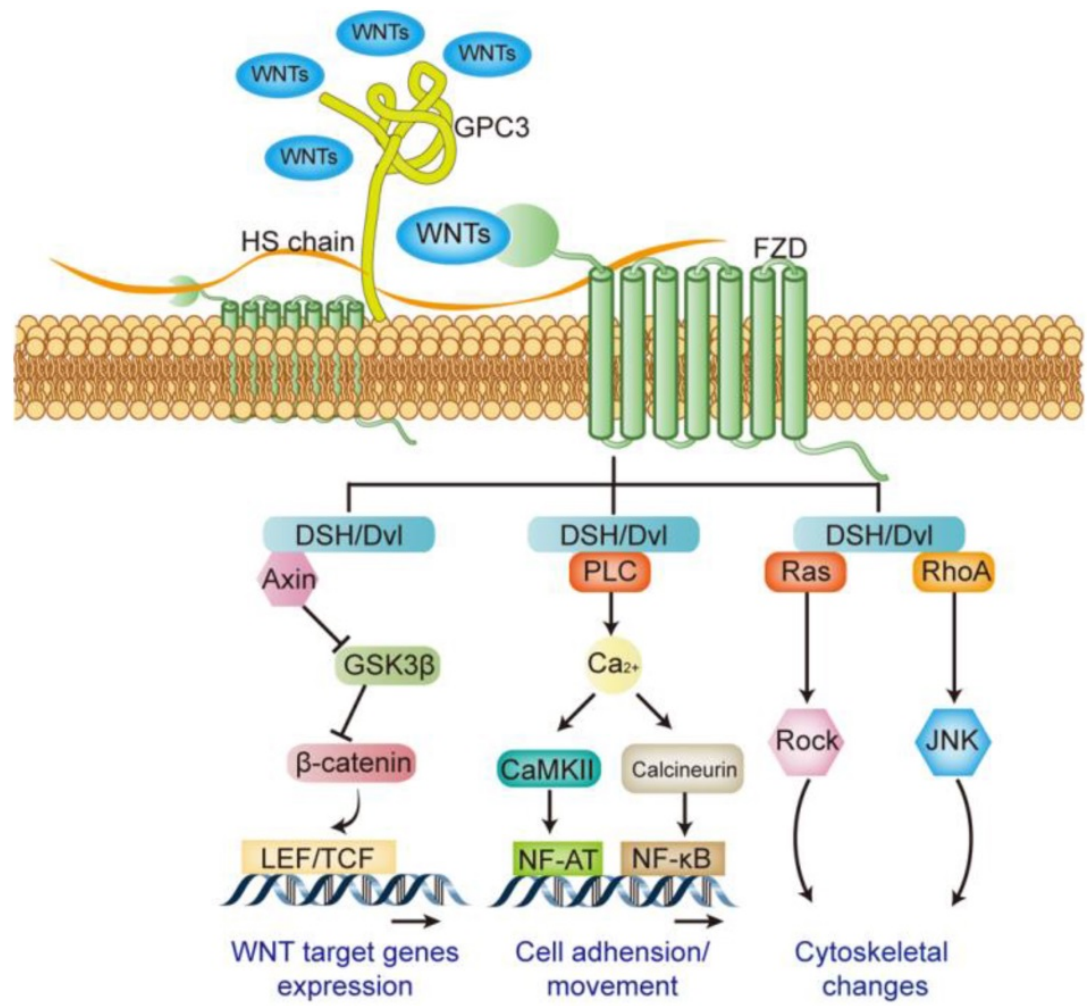

Figure 5. Regulatory effect of GPC3 on the WNT signaling pathway.

\section{Hedgehog signaling pathway}

The Hedgehog $(\mathrm{Hh})$ signaling pathway plays a key role in embryo morphogenesis, and the abnormal activation of this pathway in adults can lead to the progression of multiple tumors [47-49]. Three Hhs have been identified in mammals, including Sonic (Shh), Indian (Ihh) and Desert (Dhh). Shh is widely expressed in various tissues, and Ihh and Dhh are limitedly expressed in a few types of cell [50]. The Hh signaling is triggered by the ligand binding to the cell surface receptor celled Patched [47]. Patched is a twelve-span transmembrane protein that inhibits the activity of the $G$ protein-coupled receptor family member Smoothened (Smo) before it binds to $\mathrm{Hh}$. When $\mathrm{Hh}$ binds to Patched, it will abrogate its inhibitory effect on Smo. The activated Smo triggers the signaling cascade, causing the accumulation of transcription factors Gli1 and Gil2, which in turn regulate the expression of genes for cell proliferation, migration and differentiation [51] (Figure 6). 


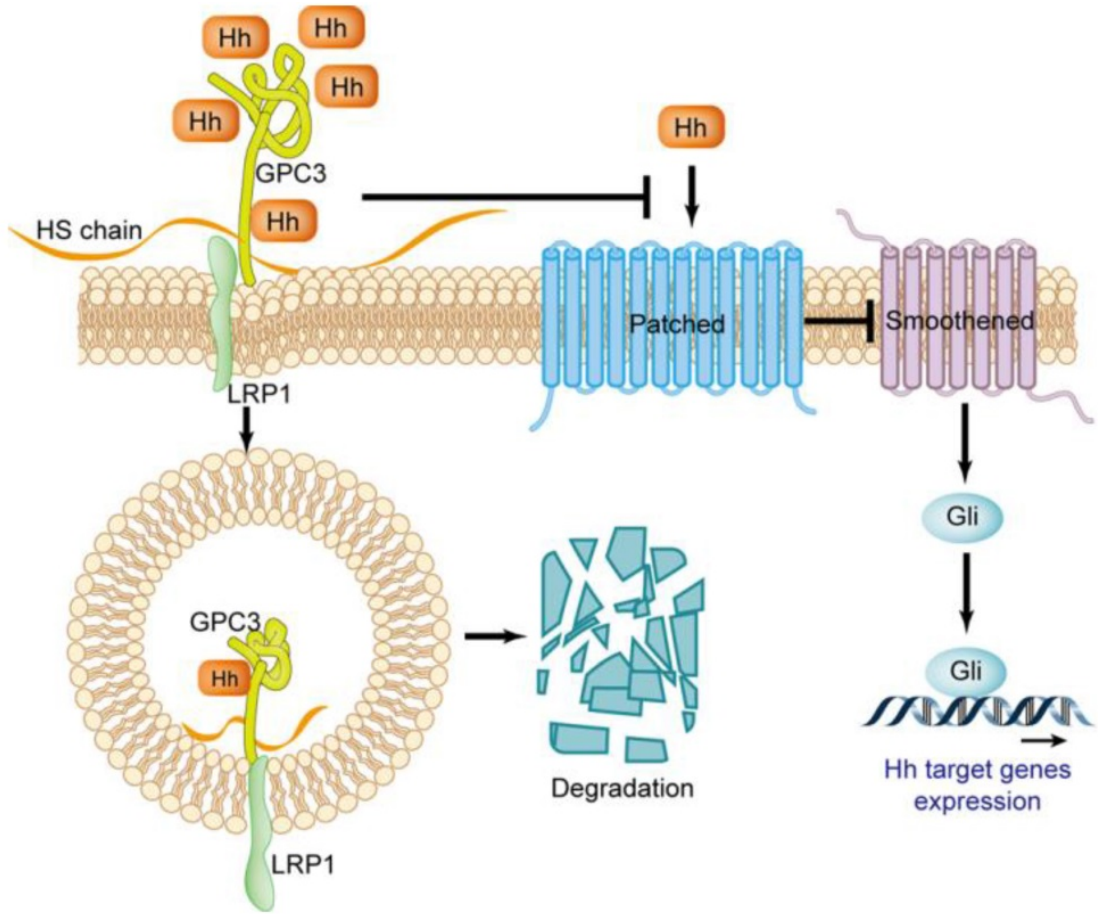

Figure 6. Regulatory effect of GPC3 on the Hedgehog signaling pathway.

In the Hedgehog signaling pathway, GPC3 is a potent negative regulator. There is an interpretation about GPC3 loss-of-function mutation resulting in SGBS attributed to excessive activation of the $\mathrm{Hh}$ signaling pathway. GPC3 can bind to Shh and Ihh with high affinity, resulting in $\mathrm{Hh}$ combined with Patched is drastically reduced, thereby inhibiting $\mathrm{Hh}$ downstream signaling [52]. The binding of GPC3 to $\mathrm{Hh}$ also causes endocytosis and degradation of the GPC3-Hh complex [52], a process that relies on the LRP1 molecule [53] (Figure 6).

\section{Other signaling pathways}

In addition to the WNT and Hh signaling pathways, GPC3 can affect pathological and physiological processes by interacting with other components in the ECM. Midorikawa Y et al. showed that the HS side chain of GPC3 can regulate cell proliferation by inhibiting the activity of fibroblast growth factor 2 (FGF2) and bone morphogenetic protein 7 (BMP-7) [54]. This inhibitory effect can be relieved by removing the HS chain via heparin-degrading endosulfatase [55]. In addition, intervention of GPC3 expression in the HCC cell line promotes TGF- $\beta 2$ expression, thereby inhibiting cell proliferation [56].

GPC3 also plays an important regulatory role in tumor metastasis. In synergy with HGF/c-Met signaling pathway, the HS side chain of GPC3 can play a role in HCC cell migration. Studies have shown that HS-targeting antibody HS20 inhibits c-Met activation in the treatment of HCC cells, thereby inhibiting HGF-mediated migration and metastasis [57]. In addition, studies have shown that GPC3 expression is negatively correlated with E-cadherin in HCC cell lines [58]; a similar correlation is also found in pathological examination, and GPC3 overexpression can activate ERK signaling pathway to induce EMT [59].

However, GPC3, as an anchored membrane protein, lacks the relevant structural domain to transmit intracellular signals, and its function on the cell surface is likely to be involved in intercellular or cell-matrix interactions, and its biological function may be far more than those revealed above. For example, Takai $\mathrm{H}$ et al. confirmed that GPC3 was highly correlated with macrophage recruitment in liver cancer tissues [60]. Further studies have found that these macrophages are mainly M2-polarized [61]. Therefore, GPC3 may play different roles in different tumor microenvironments, and its biological function may be highly related to the molecular composition in the microenvironment in which it is located. The molecular mechanism of GPC3 needs further exploration.

\section{GPC3 as a target for clinical diagnosis and its significance}

In 1997, Hsu HC et al. firstly reported that MXR7 (GPC3) cDNA has a very high positive rate in liver cancer patients [62]. Since then GPC3 has become a potential HCC marker, and a large number of studies have been conducted on the expression of GPC 3 in 
HCC tissues and serum. Lots of tissue microarray and immunohistochemical data showed that GPC3 is highly expressed in more than $70 \%$ of HCC samples, but not in normal liver tissues, benign liver lesions, liver cirrhosis or hepatitis tissues [5, 63-65]. Also, the expression level of GPC3 is correlated with prognosis [66-69]. In addition, GPC3 is also highly expressed in some other cancers such as hepatoblastoma [70], lung squamous cell carcinoma [71], ovarian yolk sac tumor [72], melanoma [73], and urothelial carcinoma [74]. Therefore, GPC3 is not only a specific biomarker and prognostic factor for $\mathrm{HCC}$, but also a potential target for a variety of tumor treatments.

\section{Expression of GPC3 in liver cancer tissues}

Hsu HC et al. firstly reported in 1997 MXR7 mRNA as a potential early HCC marker highly expressed in $74.8 \%$ of HCC tissues, and was closely correlated with elevated serum alpha-fetoprotein (AFP) levels (88\% vs 55\%) [62]. The MXR7 gene was renamed as GPC3 later. A large number of studies have shown that GPC3 is more sensitive than AFP in the diagnosis of liver cancer. GPC3 is not only expressed on the surface of tumor cells, but also released into peripheral in soluble form (sGPC3). In combination with AFP, we can further improve the sensitivity in non-invasive diagnosis of liver tumors $[5,33,70,75,76]$.

Studies by Capurro $\mathrm{M}$ et al. showed that GPC3 was expressed in $72 \%(21 / 29)$ of HCC samples, whereas GPC3 expression was not detected in samples of normal liver or benign liver disease [65]. Furthermore, the subcellular location of GPC3 was studied, and results showed that GPC3 is mainly located in the membrane and cytoplasm of HCC cells, and the most common subtype in tumors is isoform 2 (NM_004484.3) [28]. As a tumor marker with higher sensitivity than AFP, GPC3 can be used not only for the diagnosis of surgically resected samples, but also for the diagnosis of biopsy samples: $\mathrm{Li} \mathrm{B}$ et al. compared the positive rate of GPC3 in surgically resected samples and that in biopsy samples, and found that the difference between them was small $(80.0 \%$ vs $74.9 \%)$ [77].

Although the above studies have confirmed that GPC3 is a specific marker for the diagnosis of HCC, the sensitivity of a single marker cannot meet the requirement for clinical application. Many studies have proposed that HCC can be diagnosed by combination of multiple markers. The best combination of markers is GPC $3+\mathrm{HSP} 70+\mathrm{GS}$ (glutamine synthetase). This combination can specifically distinguish between hepatocellular nodules and early liver cancer and AFP-negative small liver cancer [78, 79]. A study confirmed that the specificity of the three-marker combination can reach 100\% [80]. Other studies have also suggested some potential combinations of markers, such as the combination of GP73, GPC3 and CD34 can improve the specificity of HCC diagnosis to $96.6 \%$ [81]; the combination of GPC3 and CK19 can be used for differential diagnosis of liver cancer and intrahepatic cholangiocarcinoma (accuracy was 73.5\%) [82]; GPC3 combined with Arginase-1 and HepPar-1 can further improve the diagnostic accuracy [83].

\section{Expression of GPC3 in serum of liver cancer patients}

As described above, GPC3 can be released from the cell membrane anchored site and then enter peripheral circulation. Therefore, the level of sGPC3 in serum can be an important marker for non-invasive diagnosis of HCC [65]. Studies by Capurro M et al. showed that sGPC3 was not detected in the serum of healthy donors and hepatitis patients, but $53 \%$ of HCC patients had a significant increase in sGPC3 levels [65]. Abdelgawad IA et al confirmed that the sensitivity and specificity of sGPC3 in serum of HCC patients reached 95\% [84]. However, it is worth noting that sGPC3 does not have good specificity and sensitivity in all studies. Ibrahim GH et al reported that sGPC3 is only $28 \%$ positive in HCC patients, far less than the detection rate $(80 \%)$ in patients with chronic HCV infection. This may be related to the different antibodies used by researchers in different studies. In response to this controversy, Yang SL et al. carried out a meta-analysis of 22 studies for HCC diagnosis by sGPC3 levels, and 18 studies showed that serum GPC3 was a specific biomarker for HCC, with a sensitivity and specificity in combination with other markers of $69 \%$ and $93 \%$ [85], respectively. Therefore, sGPC3 is still an important serum marker for HCC, but it needs to be combined with other markers for joint diagnosis. In addition, large numbers of samples are needed to compare the effectiveness and specificity of different commercial antibodies to determine which antibody is most suitable for clinical diagnosis.

\section{Prognostic value of GPC3 expression in patients with HCC}

Studies by Shirakawa $\mathrm{H}$ et al. showed that the positive rate of GPC3 in highly differentiated liver cancer was significantly lower than that in moderately and poorly differentiated liver cancer. The 5-year survival rate of GPC3-positive HCC patients was significantly lower than that of GPC3-negative HCC patients (54.5\% vs 87.7\%) [86]. In HBV-positive HCC patients, the survival rate of patients with high expression of GPC3 was significantly lower than that 
of patients with low or no expression of GPC3; and the expression of GPC3 was positively correlated with poor tumor differentiation, portal vein tumor thrombus and tumor lymphatic metastasis [69]. For HCC patients complicated with HBV infection /and cirrhosis and undergoing liver transplantation, GPC3 positive indicates a poor prognosis [87]. Zhang J et al. conducted a meta-analysis of 14 studies covering 2364 patients. The results showed that overexpression of GPC3 may indicate a poor prognosis. The high expression of GPC3 was significantly associated with malignant events such as poor tumor differentiation, advanced stage of tumor, vascular invasion, and HBV infection [66].

\section{Expression of GPC3 in other cancer tissues}

In addition to HCC, there are reports of GPC3 expression in other tumors. The expression of GPC 3 is significantly up-regulated in peripheral blood of patients with hepatoblastoma, but its sensitivity and specificity is significantly lower than that of AFP, and has nothing to do with prognosis [70]; however, GPC3 can be used as an immunohistochemical marker for hepatoblastoma. A meta-analysis of 4 studies including a total of 134 hepatoblastoma samples showed a positive rate of $95.5 \%(128 / 134)$ for GPC3 [88]. GPC3 has a higher positive rate in lung squamous cell carcinoma, but has a lower positive rate in lung adenocarcinoma [89-91]. A higher positive rate of GPC3 expression in yolk sac tumors (YST), including all YSTs associated with mixed germ cell tumors, it is a key marker for distinguishing between YST and clear cell carcinoma of the ovary (CCC) [72]. In melanoma, GPC3 also has a certain positive rate of expression [73, 92, 93], but some studies have shown that GPC 3 is negatively expressed in melanoma metastases [94]. In urothelial carcinoma (UC), GPC3 has a higher positive rate in malignant UC (43.6\% vs 13.3\%), which is not expressed in normal urothelium. It can be used as a marker when it is difficult to distinguish between low-grade and high-grade tumors [95].

\section{The treatment strategy of liver cancer with GPC3 as the target}

Many studies have shown that GPC3 is specifically expressed on the surface of most HCC cells, but is hardly expressed in other tissues of adults. Therefore, the researchers designed a variety of treatment strategies targeting GPC 3 to achieve precise treatment of HCC: antibody-based drugs targeting GPC3, chimeric antigen receptor-modified cells adoptive immunotherapy targeting GPC3, GPC3-related tumor vaccines, antibody-drug conjugate and immunotoxins based on GPC3 antibodies.

\section{Application of GPC3 antibody in the treatment of liver cancer}

GC33 is a monoclonal antibody targeting the carboxyl terminal subunit of the GPC3 molecule. In mouse ectopic and in situ GPC3-positive HCC xenograft models, GC33 can significantly inhibit tumor growth [96]; its tumor inhibition efficacy is mainly through antibody-dependent cell-mediated cytotoxicity (ADCC) [97]. The GC33 humanized antibody is currently the only one that has entered the clinical trial stage [98-100]: its phase I clinical trial showed that the GC33 antibody had good safety, and the high dose group did not show significant adverse reactions. The median time to progression in patients with high expression of GPC3 was significantly higher than that in patients with low expression of GPC3 (26 weeks vs 7 weeks), and nearly half of the patients were stable $(7 / 13$, no progression or remission); however, the results of the phase II clinical trial did not achieve the anticipated goal, in patients with GPC3-positive HCC, treatment with GC33 did not benefit the patients, which may be related to the specific immune microenvironment of liver cancer. This result suggests that antibody therapy targeting GPC3 alone may have limited efficacy.

In addition to GC33, several other therapeutic GPC3 antibodies were screened. Based on the GC33 antibody, Ishiguro $\mathrm{T}$ et al. have developed a bispecific antibody ERY974 targeting GPC3 and CD3. ERY974 has a good killing effect on a variety of GPC3 high expression tumors, and can convert "cold tumor" into a highly inflammatory state "hot tumor". It has now entered phase I clinical trials (NCT02748837i) [101]. Zhang YF et al. identified a YP7 antibody targeting the carboxyl terminal epitope of GPC3, and its scFv-Fc antibody showed better anti-tumor effect in a nude mouse liver cancer xenograft model [102]. Feng M et al. identified a high-affinity antibody HN3 targeting full-length GPC3. This antibody can inhibit the proliferation of GPC3-positive cells by arresting the cell cycle in G1, and has a significant inhibitory effect on the growth of HCC xenografts in nude mice [103]. Gao W et al. identified antibody HS20 targeting heparan sulfate chain of GPC3, which blocked Wnt/ $\beta$-catenin signaling, and inhibited WNT3a-dependent cell proliferation and HCC xenografts growth by blocking the interaction between Wnt3a and its ligand [45]. Information on GPC3 antibodies is summarized in Table 1.

\section{Antibody-drug conjugate and immunotoxins based on GPC3 antibodies}

An antibody-drug conjugate (ADC) is a precision therapeutic drug developed based on antibodies, consisting of a monoclonal antibody with 
specific targeting, a chemically toxic molecule with cytotoxicity, and an adaptor that connects the two. It can concentrate the highly toxic drugs on the tumor site to exert the killing effect, thereby expanding the therapeutic window of small molecular toxins, and significantly reducing the side effects while accurately killing the tumor [104]. Based on YP7 antibody, Fu Y et al. constructed an ADC coupled with Duocarmycin SA or pyrrolobenzodiazepine dimer - hYP7-DC and hYP7-PC. These two drugs can kill the tumor cells at pMol concentration [105].

Table 1. GPC3 related antibodies

\begin{tabular}{lllll}
\hline Antibody & Affinity & Antigen & Format & Refs. \\
\hline GC33 & $0.67 \mathrm{nM}$ & C terminal (524-563) & $\mathrm{mAb}$ & {$[96]$} \\
$\mathrm{HN} 3$ & $0.6 \mathrm{nM}$ & Whole protein & $\mathrm{VH}+\mathrm{hFc}$ & {$[103]$} \\
YP7 & $10 \mathrm{nM}$ & C terminal (511-560) & $\mathrm{scFv}+\mathrm{Fc}$ & {$[102]$} \\
HS20 & $0.28 \mathrm{nM}$ & Heparan sulfate & $\mathrm{mAb}$ & {$[45]$} \\
ERY974 & $0.67 \mathrm{nM}$ & GPC3 \& CD3 & Bispecific antibody & {$[101]$} \\
\hline
\end{tabular}

An immunotoxin is a pharmacologically active biological preparation constructed from an antibody or a molecular ligand having a specific targeting function coupled to a toxin protein [106, 107]. Pseudomonas exotoxin A (PE-A) is the most commonly used toxin fragment in immunotoxins and can cause cell death by inhibiting protein synthesis in cells [106]. Several immunotoxins were derived from combination of PE-A and GPC3 antibodies: Gao W et al. constructed immunotoxins YP7-PE38 and HN3-PE38, both have good anti-tumor activity in vivo and in vitro, and can induce regression of GPC3 positive xenografts [108]. The same research team truncated the PE-A protein molecule to construct the immunotoxin HN3-mPE24, which also significantly prolonged the survival time of tumor-bearing mice [109]. When YP7 scFv identified by Zhang YF et al. was coupled with Pseudomonas Exotoxin A (PE38KDEL), it showed a potent anti-tumor effect in a nude mouse xenograft model [102].

Photoimmunotherapy is a new antibody-based biologic agent invented by the Kobayashi team in 2011. It is specifically enriched in carcinoma nest after the near-infrared phthalocyanine dye IR700 coupling with a specific antibody or biomacromolecule, and cell death can be induced by irradiating the drug-bound target cells with near-infrared light [110]. The team designed two kinds of photoimmunotherapy agents, IR700-YP7 and IR700-HN3, based on YP7 antibody and NH3, both of which can significantly inhibit tumor growth $[111,112]$.

\section{Therapeutic strategies based on chimeric antigen receptors}

Chimeric antigen receptor (CAR) refers to a cell surface fusion protein containing an antigen recognition fragment, an immune cell receptor activating molecule, and a costimulatory signal molecule assembled by genetic engineering; after transfecting immune cells (such as NK, T cells, etc.) to express chimeric antigen receptors on the surface, CAR can accurately identify and direct immune cells to kill tumor cells [113]. Several groups such as Gao H et al. [114], Li K et al. [71], Shimizu Y et al. [115], and Jiang $Z$ et al. [116] constructed CAR-T based on GC33 antibody. These CAR-Ts have good killing effects on GPC3-positive cell lines or PDX. In order to further improve the CAR-T specificity and reduce the risk of off-target, Chen C et al. designed GPC3/ASGR1 bispecific CAR-T, which can specifically kill $\mathrm{GPC}^{+}{ }^{+} \mathrm{ASGR} 1^{+} \mathrm{HCC}$ [117]. In order to further enhance the killing effect of GPC3 CAR-T, Pan Z et al. co-expressed soluble PD1 (sPD1) fragment with CAR, and sPD1 can protect CAR-T from $\mathrm{T}$ cell depletion induced by PD1/PDL1 signaling pathway when co-incubated with target cells [118]; Guo X et al. found that knockout PD1 in CAR-T by CAS9 can block the downstream signaling of PD1 and significantly enhance the expression of Akt phosphorylation and anti-apoptotic protein Bcl-xL, improving its anti-tumor effect [119]. Zhao $\mathrm{R}$ et al. introduced the intracellular domain of DAP10 into CAR, which significantly improved the killing activity of CAR-T [120]. At present, 12 clinical trials have been carried out for the GPC3 CAR-T, as shown in Table 2.

Although CAR-T has a very high response rate in cancer therapy, it also has certain side effects, including off-target effects, cytokine storms and extremely high risk of GVHD. The NK cells, with a short physiological cycle (1 2 weeks) and extensive tumor killing ability, has attracted the attention of researchers. NK cells are a kind of lymphocytes that can kill tumor cells independent on MHC. After recognizing tumor cells, NK cells can cause target cell apoptosis by releasing perforin and granzyme, expressing TNF superfamily members and mediating ADCC. Despite these, compared with T cells, primary NK cells have a series of disadvantages such as limited in vitro amplification efficiency and extremely low transfection efficiency. Therefore, many studies have focused on NK-92 cell lines. NK92 is a highly cytotoxic NK cell line that can be continuously and uniformly amplified, and can be applied to establish a stable CAR-NK cell line [121], and has been proved to be excellent in safety by many clinical trials. Nowadays, several CAR-NK products targeting GPC3 have already been developed. Yu M et al. constructed a CAR-NK cell line targeting GPC3 based on hu9f2 antibody, which has good killing activity both in vitro and in vivo [122]. 
Table 2. Clinical Application of GPC3 CAR-T (Update to 2018)

\begin{tabular}{llll}
\hline Clinic trail & Indication & Status & Phase \\
\hline NCT02395250 & HCC & Completed & I \\
NCT03084380 & HCC & Not yet recruiting & II \\
NCT02905188 & HCC & Not yet recruiting & I \\
NCT02932956 & Pediatric Liver Cancer & Recruiting & I \\
NCT02876978 & LSCC & Recruiting & I \\
NCT02715362 & HCC & Recruiting & II \\
NCT03130712 & HCC & Recruiting & II \\
NCT03198546 & HCC\& LSCC & Recruiting & I \\
NCT02723942 & HCC & Completed & II \\
NCT03146234 & HCC & Recruiting & Not Applicable \\
NCT03302403 & HCC & Not yet recruiting & Not Applicable \\
NCT02959151 & HCC & Unknown & II \\
\hline
\end{tabular}

\section{GPC3 tumor vaccine}

A tumor vaccine, which contains a tumor antigen gene or a tumor antigen peptide, can activate acquired immune function to attack tumor cells and prevent tumor growth, metastasis, and recurrence by inducing body-specific cellular immunity and humoral immunity. Tumor antigens include tumor specific antigen (TSA) and tumor associated antigen (TAA). As a typical TSA, GPC3 is specifically expressed on the surface of HCC cells, but is hardly expressed in other cells in healthy adults [123]. Therefore, a lot of research results about GPC3 have popped up in the field of tumor vaccine application.

Nakatsura $\mathrm{T}$ et al. firstly identified a specific GPC3 linear epitope GPC3 298-306 (EYILSLEEL) peptide in BALB/c mice, which can induce tumor rejection and large numbers of $\mathrm{CD} 8+\mathrm{T}$ cells into the tumor after xenograft in mice of the tumor cells transfected with this epitope [124]; later this group identified the linear epitope GPC $3_{144-152}$ (FVGEFFTDV) peptide, which induces peptide-reactive CTLs in HLA-A2.1 transgenic mice without inducing autoimmunity, and activates CTLs in HCC patients, and these CTLs can significantly kill tumors in the PDX model [125]. Based on the above results, this team conducted a phase I clinical trial of GPC 3 tumor vaccine in patients with advanced liver cancer [126]: 33 patients with advanced HCC were inoculated with GPC3 vaccine, and the results showed that the GPC3 vaccine was well tolerated, and GPC3 specific CTL response was induced in 30 patients. 19 patients were stable 2 months after the start of treatment, and 4 of 19 patients with stable condition had tumor necrosis or regression [127]; one 62-year-old sorafenib-resistant liver cancer patient after receiving GPC3 peptide vaccine, most of the intrahepatic tumors had central necrosis, and GPC3-specific CTLs specifically infiltrated the tumor site and did not attack normal liver tissue [128]. In addition, the vaccine also achieved good reactivity in clinical trials of GPC3-positive ovarian cancer patients. Two chemotherapy-resistant ovarian cancer patients respectively received GPC3 vaccine injections once every two weeks (6 times in total), a 42-year-old patient suffered advanced recurrent ovarian cancer with liver and retroperitoneal lymph node metastasis showed partial response at 10 weeks after vaccination, and another 67-year-old woman with multiple lymph node metastases remained stable for more than one year [129]. At present, the phase II clinical trial of the vaccine for HCC has finished. The recurrent rate of 35 cases of GPC3 vaccine after surgery is lower than that of 33 cases of surgery alone, suggesting that the vaccine has better anti-tumor effect [130].

\section{Conclusion}

Since GPC3 was revealed as a new marker of liver cancer in 1997, its biological function and expression pattern have been gradually identified, and it has evolved from a potential tumor marker to an important indicator for clinical detection, and a series of GPC3 target therapies has been developed. Compared with the traditional HCC marker AFP, the expression pattern of GPC3 anchored on membrane has great clinical transformation potential:

- As a target of in vivo imaging, it can accurately locate the liver cancer before treatment, and determine the stage of liver cancer and surgical margins by combining AI technology in image group as well as the non-invasive detection of curative effect and tumor recurrence after surgery;

- Secretory GPC3 provides a reliable new target for early non-invasive screening and diagnosis of tumors;

- Antibody-based drugs derived from GPC3 antibodies and adoptive immunotherapy provide a more accurate and effective way for the treatment of liver cancer.

Despite these, GPC3 still has many technical bottlenecks in clinical applications. The mechanism of GPC3 in the process of liver cancer has not been thoroughly explained. Although it is clearly understood that GPC3 plays an important role in the regulation of WNT and Hedgehog signaling pathways, it is still unclear whether GPC3 can determine the cell differentiation in embryonic development and tumorigenesis. As a membrane-anchored protein, GPC3 lacks the relevant domain that transmits intracellular signals, and its function on the cell surface is likely to be involved in intercellular or cell-to-matrix interactions: GPC3 may be involved in formation of lipid raft rich in cholesterol and glycosphingolipid, the small $G$ protein on the cytoplasmic surface of this lipid raft may be involved in the transduction of GPC3 downstream signaling; in 
addition, the interaction of GPC3 with other cells in the microenvironment may also regulate important pathophysiology process. It is possible that GPC3 is a "chameleon molecule", whose biological action is determined by the biological interface of "membrane-matrix". The molecular composition at this interface determines the biological function of GPC3. These hypotheses also need to be confirmed.

Many previous studies have shown that single anti-GPC3 treatments, including utilization of GC33 or HN3 antibody were not sufficient for elimination of hepatocellular carcinoma. Recombinant immunotoxins and bispecific antibodies developed from GPC3 antibodies have achieved marked therapeutic effects in animal experiments, but their clinical efficacy still need to be verified by clinical trials.

Construction of chimeric antigen receptormodified immune cells targeting GPC3 seems to be an attractive therapeutic strategy, but it still faces many challenges. Firstly, the microenvironment of liver cancer is always immunosuppressive, such as perfoming high concentration of IL-10 and TFG- $\beta$, which directly inhibit the activation of CAR-bearing cells. Secondly, liver cancer, especially advanced liver cancer has special metabolic features, including hypoxia, high lactic acid, nutrient deficiency, etc., which directly leads to dyfunction of immune cells after entering the microenvironment. Finally, some tumors were surrounding by myeloid-derived suppressor cells (MDSC) and $\mathrm{T}$ regulatory cells (Tregs), which are known to dampen the immune response and inhibit $\mathrm{T}$ cells trying to move into the tumor.

To solve above problems, there are several potential strategies to make anti-GPC3-CAR a true "liver cancer killer". For microenvironment immunosuppression, the chimeric antigen receptor structure can be furtherly engineered to provide sufficient activation signals. For example, the ligandrecognition domain of IL-10R and TGF- $\beta$ R can be conjgated to $\mathrm{N}$-terminal of $\mathrm{scFv}$, and then transform suppression signal into activation signal. Moveover, CAR-carriers might be geneticlly engineered to adapt the tumor metabolism. To be specific, CRISPR/CAS9 in vivo screening could be performed to find key molecules for the immune cells to survive and activate in a certain metabolic niche. Finally, some studies have shown that several chemical compounds like all-trans retinoic acid (ATRA) had activity in reducing MDSC in tumor nest. The combination therapy with anti-GPC3 CAR-T and compounds like ATRA might further enhance antitumor response.

Subsequently, is the most essential question is that the absence of GPC3 is not lethal to tumor cells. Even if targeting GPC3 strategy could eliminate all
GPC3-positive cells, GPC3-negative tumor may grow under such treatment pressure and become resistant. To solve this problem, in addition to finding new tumor therapeutic targets, it is necessary to study the regulation of GPC3 expression to prevent the emergence of drug-resistant clones during the treatment.

\section{Acknowledgments}

This work was supported by the National Natural Science Foundation of China (81602526, 81972683 and 81602497).

\section{Competing Interests}

The authors have declared that no competing interest exists.

\section{References}

1. Bernard W. Stewart CPW. World Cancer Report 2014. France: the International Agency for Research on Cancer; 2014

2. Chen W, Zheng R, Baade PD, Zhang S, Zeng H, Bray F, et al. Cancer statistics in China, 2015. CA: a cancer journal for clinicians. 2016.

3. Fan ST, Mau Lo C, Poon RT, Yeung C, Leung Liu C, Yuen WK, et al. Continuous improvement of survival outcomes of resection of hepatocellular carcinoma: a 20-year experience. Annals of surgery. 2011; 253: 745-58.

4. Toso C, Mentha G, Majno P. Liver transplantation for hepatocellular carcinoma: five steps to prevent recurrence. American journal of transplantation : official journal of the American Society of Transplantation and the American Society of Transplant Surgeons. 2011; 11: 2031-5.

5. Sun B, Huang Z, Wang B, Yu Y, Lin S, Luo L, et al. Significance of Glypican-3 (GPC3) Expression in Hepatocellular Cancer Diagnosis. Medical science monitor : international medical journal of experimental and clinical research. 2017; 23: 850-5.

6. Hyodo I, Mizuno M, Yamada G, Tsuji T. Distribution of asialoglycoprotein receptor in human hepatocellular carcinoma. Liver. 1993; 13: 80-5.

7. Sciot R, Paterson AC, van Eyken P, Callea F, Kew MC, Desmet VJ. Transferrin receptor expression in human hepatocellular carcinoma: an immunohistochemical study of 34 cases. Histopathology. 1988; 12: 53-63.

8. Shapiro JM, Chung W, Ogawa K, Barker L, Carlson R, Wands JR, et al. Identification of Tumor Antigen AF20 as Glycosylated Transferrin Receptor 1 in Complex with Heat Shock Protein 90 and/or Transporting ATPase. PloS one. 2016; 11: e0165227.

9. Reynaert H, Rombouts K, Vandermonde A, Urbain D, Kumar U, Bioulac-Sage $\mathrm{P}$, et al. Expression of somatostatin receptors in normal and cirrhotic human liver and in hepatocellular carcinoma. Gut. 2004; 53: 1180-9.

10. Shao GZ, Zhou RL, Zhang QY, Zhang Y, Liu JJ, Rui JA, et al. Molecular cloning and characterization of LAPTM4B, a novel gene upregulated in hepatocellular carcinoma. Oncogene. 2003; 22: 5060-9.

11. Filmus J, Selleck SB. Glypicans: proteoglycans with a surprise. The Journal of clinical investigation. 2001; 108: 497-501.

12. Bishop JR, Schuksz M, Esko JD. Heparan sulphate proteoglycans fine-tune mammalian physiology. Nature. 2007; 446: 1030-7.

13. Kirkpatrick CA, Selleck SB. Heparan sulfate proteoglycans at a glance. Journal of cell science. 2007; 120: 1829-32.

14. De Cat B, David G. Developmental roles of the glypicans. Seminars in cell \& developmental biology. 2001; 12: 117-25.

15. Filmus J. Glypicans in growth control and cancer. Glycobiology. 2001; 11: 19R-23R.

16. Liu B, Paranjpe S, Bowen WC, Bell AW, Luo JH, Yu YP, et al. Investigation of the role of glypican 3 in liver regeneration and hepatocyte proliferation. The American journal of pathology. 2009; 175: 717-24.

17. Thul PJ, Lindskog C. The human protein atlas: A spatial map of the human proteome. Protein science : a publication of the Protein Society. 2018; 27: 233-44.

18. Wu C, Jin X, Tsueng G, Afrasiabi C, Su AI. BioGPS: building your own mash-up of gene annotations and expression profiles. Nucleic acids research. 2016; 44: D313-6.

19. Aikawa T, Whipple CA, Lopez ME, Gunn J, Young A, Lander AD, et al. Glypican-1 modulates the angiogenic and metastatic potential of human and mouse cancer cells. The Journal of clinical investigation. 2008; 118: 89-99.

20. Whipple CA, Young AL, Korc M. A KrasG12D-driven genetic mouse model of pancreatic cancer requires glypican-1 for efficient proliferation and angiogenesis. Oncogene. 2012; 31: 2535-44.

21. Matsuda K, Maruyama H, Guo F, Kleeff J, Itakura J, Matsumoto Y, et al. Glypican-1 is overexpressed in human breast cancer and modulates the 
mitogenic effects of multiple heparin-binding growth factors in breast cancer cells. Cancer research. 2001; 61: 5562-9.

22. Hara H, Takahashi T, Serada S, Fujimoto M, Ohkawara T, Nakatsuka R, et al. Overexpression of glypican-1 implicates poor prognosis and their chemoresistance in oesophageal squamous cell carcinoma. British journal of cancer. 2016; 115: 66-75.

23. Su G, Meyer K, Nandini CD, Oiao D, Salamat S, Friedl A. Glypican-1 is frequently overexpressed in human gliomas and enhances FGF-2 signaling in glioma cells. The American journal of pathology. 2006; 168: 2014-26.

24. Cao J, Ma J, Sun L, Li J, Qin T, Zhou C, et al. Targeting glypican-4 overcomes 5-FU resistance and attenuates stem cell-like properties via suppression of Wnt/beta-catenin pathway in pancreatic cancer cells. Journal of cellular biochemistry. 2018; 119: 9498-512.

25. Williamson D, Selfe J, Gordon T, Lu YJ, Pritchard-Jones K, Murai K, et al. Role for amplification and expression of glypican-5 in rhabdomyosarcoma. Cancer research. 2007; 67: 57-65.

26. Karapetsas A, Giannakakis A, Dangaj D, Lanitis E, Kynigopoulos S, Lambropoulou M, et al. Overexpression of GPC6 and TMEM132D in Early Stage Ovarian Cancer Correlates with CD8+ T-Lymphocyte Infiltration and Increased Patient Survival. BioMed research international. 2015; 2015: 712438.

27. Li N, Gao W, Zhang YF, Ho M. Glypicans as Cancer Therapeutic Targets. Trends in cancer. 2018; 4: 741-54.

28. Ho M, Kim H. Glypican-3: a new target for cancer immunotherapy. European journal of cancer. 2011; 47:333-8.

29. Papadopoulos JS, Agarwala R. COBALT: constraint-based alignment tool for multiple protein sequences. Bioinformatics. 2007; 23: 1073-9.

30. Nielsen H. Predicting Secretory Proteins with SignalP. Methods in molecular biology. 2017; 1611: 59-73.

31. Pilia G, Hughes-Benzie RM, MacKenzie A, Baybayan P, Chen EY, Huber R, et al. Mutations in GPC3, a glypican gene, cause the Simpson-Golabi-Behmel overgrowth syndrome. Nature genetics. 1996; 12: 241-7.

32. Cano-Gauci DF, Song HH, Yang H, McKerlie C, Choo B, Shi W, et al. Glypican-3-deficient mice exhibit developmental overgrowth and some of the abnormalities typical of Simpson-Golabi-Behmel syndrome. The Journal of cell biology. 1999; 146: 255-64.

33. Zhou F, Shang W, Yu X, Tian J. Glypican-3: A promising biomarker for hepatocellular carcinoma diagnosis and treatment. Medicinal research reviews. 2018; 38: 741-67.

34. Selleck SB. Overgrowth syndromes and the regulation of signaling complexes by proteoglycans. American journal of human genetics. 1999; 64: 372-7.

35. Yan D, Lin X. Opposing roles for glypicans in Hedgehog signalling. Nature cell biology. 2008; 10: 761-3.

36. Hou S, Maccarana M, Min TH, Strate I, Pera EM. The secreted serine protease xHtrA1 stimulates long-range FGF signaling in the early Xenopus embryo. Developmental cell. 2007; 13: 226-41.

37. Gallagher J. Messages in the matrix: proteoglycans go the distance. Developmental cell. 2007; 13: 166-7.

38. Nusse R, Clevers H. Wnt/beta-Catenin Signaling, Disease, and Emerging Therapeutic Modalities. Cell. 2017; 169: 985-99.

39. Niehrs C. The complex world of WNT receptor signalling. Nature reviews Molecular cell biology. 2012; 13: 767-79.

40. Klaus A, Birchmeier W. Wnt signalling and its impact on development and cancer. Nature reviews Cancer. 2008; 8: 387-98.

41. MacDonald BT, He X. Frizzled and LRP5/6 receptors for Wnt/beta-catenin signaling. Cold Spring Harbor perspectives in biology. 2012; 4 .

42. $\mathrm{Wu} \mathrm{CH}$, Nusse R. Ligand receptor interactions in the Wnt signaling pathway in Drosophila. The Journal of biological chemistry. 2002; 277: 41762-9.

43. Tamai K, Semenov M, Kato Y, Spokony R, Liu C, Katsuyama Y, et al. LDL-receptor-related proteins in Wnt signal transduction. Nature. 2000; 407: 530-5

44. Capurro MI, Xiang YY, Lobe C, Filmus J. Glypican-3 promotes the growth of hepatocellular carcinoma by stimulating canonical Wnt signaling. Cancer research. 2005; 65: 6245-54.

45. Gao W, Kim H, Feng M, Phung Y, Xavier CP, Rubin JS, et al. Inactivation of Wnt signaling by a human antibody that recognizes the heparan sulfate chains of glypican-3 for liver cancer therapy. Hepatology. 2014; 60: 576-87.

46. Capurro M, Martin T, Shi W, Filmus J. Glypican-3 binds to Frizzled and plays a direct role in the stimulation of canonical Wnt signaling. Journal of cell science. 2014; 127: 1565-75.

47. Briscoe J, Therond PP. The mechanisms of Hedgehog signalling and its roles in development and disease. Nature reviews Molecular cell biology. 2013; 14: 416-29.

48. Rubin LL, de Sauvage FJ. Targeting the Hedgehog pathway in cancer. Nature reviews Drug discovery. 2006; 5: 1026-33.

49. Pak E, Segal RA. Hedgehog Signal Transduction: Key Players, Oncogenic Drivers, and Cancer Therapy. Developmental cell. 2016; 38: 333-44.

50. Pathi S, Pagan-Westphal S, Baker DP, Garber EA, Rayhorn P, Bumcrot D, et al. Comparative biological responses to human Sonic, Indian, and Desert hedgehog. Mechanisms of development. 2001; 106: 107-17.

51. Robbins DJ, Fei DL, Riobo NA. The Hedgehog signal transduction network. Science signaling. 2012; 5: re6.

52. Capurro MI, Xu P, Shi W, Li F, Jia A, Filmus J. Glypican-3 inhibits Hedgehog signaling during development by competing with patched for Hedgehog binding. Developmental cell. 2008; 14: 700-11.
53. Capurro MI, Shi W, Filmus J. LRP1 mediates Hedgehog-induced endocytosis of the GPC3-Hedgehog complex. Journal of cell science. 2012; 125: 3380-9.

54. Midorikawa $Y$, Ishikawa S, Iwanari H, Imamura T, Sakamoto H, Miyazono K, et al. Glypican-3, overexpressed in hepatocellular carcinoma, modulates FGF2 and BMP-7 signaling. International journal of cancer. 2003; 103: 455-65.

55. Lai JP, Sandhu DS, Yu C, Han T, Moser CD, Jackson KK, et al. Sulfatase 2 up-regulates glypican 3, promotes fibroblast growth factor signaling, and decreases survival in hepatocellular carcinoma. Hepatology. 2008; 47: 1211-22.

56. Sun CK, Chua MS, He J, So SK. Suppression of glypican 3 inhibits growth of hepatocellular carcinoma cells through up-regulation of TGF-beta2. Neoplasia. 2011; 13: 735-47.

57. Gao W, Kim H, Ho M. Human Monoclonal Antibody Targeting the Heparan Sulfate Chains of Glypican-3 Inhibits HGF-Mediated Migration and Motility of Hepatocellular Carcinoma Cells. PloS one. 2015; 10: e0137664.

58. Qi XH, Wu D, Cui HX, Ma N, Su J, Wang YT, et al. Silencing of the glypican-3 gene affects the biological behavior of human hepatocellular carcinoma cells. Molecular medicine reports. 2014; 10: 3177-84.

59. Wu $\mathrm{Y}$, Liu $\mathrm{H}$, Weng $\mathrm{H}$, Zhang $\mathrm{X}$, Li $\mathrm{P}$, Fan CL, et al. Glypican-3 promotes epithelial-mesenchymal transition of hepatocellular carcinoma cells through ERK signaling pathway. International journal of oncology. 2015; 46: 1275-85.

60. Takai $\mathrm{H}$, Kato A, Kato $\mathrm{C}$, Watanabe T, Matsubara $\mathrm{K}$, Suzuki M, et al. The expression profile of glypican-3 and its relation to macrophage population in human hepatocellular carcinoma. Liver international : official journal of the International Association for the Study of the Liver. 2009; 29: 1056-64.

61. Takai H, Ashihara M, Ishiguro T, Terashima H, Watanabe T, Kato A, et al. Involvement of glypican-3 in the recruitment of M2-polarized tumor-associated macrophages in hepatocellular carcinoma. Cancer biology \& therapy. 2009; 8: 2329-38.

62. Hsu HC, Cheng W, Lai PL. Cloning and expression of a developmentally regulated transcript MXR7 in hepatocellular carcinoma: biological significance and temporospatial distribution. Cancer research. 1997; 57: 5179-84.

63. Jia HL, Ye QH, Qin LX, Budhu A, Forgues M, Chen Y, et al. Gene expression profiling reveals potential biomarkers of human hepatocellular carcinoma. Clinical cancer research : an official journal of the American Association for Cancer Research. 2007; 13: 1133-9.

64. Baumhoer D, Tornillo L, Stadlmann S, Roncalli M, Diamantis EK, Terracciano LM. Glypican 3 expression in human nonneoplastic, preneoplastic, and neoplastic tissues: a tissue microarray analysis of 4,387 tissue samples. American journal of clinical pathology. 2008; 129: 899-906

65. Capurro M, Wanless IR, Sherman M, Deboer G, Shi W, Miyoshi E, et al. Glypican-3: a novel serum and histochemical marker for hepatocellular carcinoma. Gastroenterology. 2003; 125: 89-97.

66. Zhang J, Zhang M, Ma H, Song X, He L, Ye X, et al. Overexpression of glypican-3 is a predictor of poor prognosis in hepatocellular carcinoma: An updated meta-analysis. Medicine. 2018; 97: e11130.

67. Haruyama Y, Kataoka H. Glypican-3 is a prognostic factor and an immunotherapeutic target in hepatocellular carcinoma. World journal of gastroenterology. 2016; 22: 275-83.

68. Ofuji K, Saito K, Suzuki S, Shimomura M, Shirakawa H, Nobuoka D, et al. Perioperative plasma glypican-3 level may enable prediction of the risk of recurrence after surgery in patients with stage I hepatocellular carcinoma. Oncotarget. 2017; 8: 37835-44.

69. Wang L, Pan L, Yao M, Cai Y, Dong Z, Yao D. Expression of oncofetal antigen glypican-3 associates significantly with poor prognosis in HBV-related hepatocellular carcinoma. Oncotarget. 2016; 7: 42150-8.

70. Zhou S, O'Gorman MR, Yang F, Andresen K, Wang L. Glypican 3 as a Serum Marker for Hepatoblastoma. Scientific reports. 2017; 7: 45932.

71. Li K, Pan X, Bi Y, Xu W, Chen C, Gao H, et al. Adoptive immunotherapy using $\mathrm{T}$ lymphocytes redirected to glypican-3 for the treatment of lung squamous cell carcinoma. Oncotarget. 2016; 7: 2496-507.

72. Esheba GE, Pate LL, Longacre TA. Oncofetal protein glypican-3 distinguishes yolk sac tumor from clear cell carcinoma of the ovary. The American journal of surgical pathology. 2008; 32: 600-7.

73. Nakatsura T, Nishimura Y. Usefulness of the novel oncofetal antigen glypican-3 for diagnosis of hepatocellular carcinoma and melanoma. BioDrugs : clinical immunotherapeutics, biopharmaceuticals and gene therapy. 2005; 19: 71-7.

74. Umezu T, Shibata K, Kajiyama H, Yamamoto E, Nawa A, Kikkawa F. Glypican-3 expression predicts poor clinical outcome of patients with early-stage clear cell carcinoma of the ovary. Journal of clinical pathology. 2010; 63: 962-6.

75. El-Saadany S, El-Demerdash T, Helmy A, Mayah WW, El-Sayed Hussein B, Hassanien M, et al. Diagnostic Value of Glypican-3 for Hepatocellular Carcinomas. Asian Pacific journal of cancer prevention : APJCP. 2018; 19: 811-7.

76. Chen C, Huang X, Ying Z, Wu D, Yu Y, Wang X, et al. Can glypican-3 be a disease-specific biomarker? Clinical and translational medicine. 2017; 6: 18

77. Li B, Liu H, Shang HW, Li P, Li N, Ding HG. Diagnostic value of glypican-3 in alpha fetoprotein negative hepatocellular carcinoma patients. African health sciences. 2013; 13: 703-9.

78. Tremosini S, Forner A, Boix L, Vilana R, Bianchi L, Reig M, et al. Prospective validation of an immunohistochemical panel (glypican 3, heat shock protein 70 and glutamine synthetase) in liver biopsies for diagnosis of very early hepatocellular carcinoma. Gut. 2012; 61: 1481-7. 
79. Di Tommaso L, Franchi G, Park YN, Fiamengo B, Destro A, Morenghi E, et al. Diagnostic value of HSP70, glypican 3, and glutamine synthetase in hepatocellular nodules in cirrhosis. Hepatology. 2007; 45: 725-34.

80. Di Tommaso L, Destro A, Seok JY, Balladore E, Terracciano L, Sangiovanni A, et al. The application of markers (HSP70 GPC3 and GS) in liver biopsies is useful for detection of hepatocellular carcinoma. Journal of hepatology. 2009; 50: 746-54.

81. Yao S, Zhang J, Chen H, Sheng Y, Zhang X, Liu Z, et al. Diagnostic value of immunohistochemical staining of GP73, GPC3, DCP, CD34, CD31, and reticulin staining in hepatocellular carcinoma. The journal of histochemistry and cytochemistry : official journal of the Histochemistry Society. 2013; 61: $639-48$

82. Ryu HS, Lee K, Shin E, Kim SH, Jing J, Jung HY, et al. Comparative analysis of immunohistochemical markers for differential diagnosis of hepatocelluar carcinoma and cholangiocarcinoma. Tumori. 2012; 98: 478-84.

83. Timek DT, Shi J, Liu H, Lin F. Arginase-1, HepPar-1, and Glypican-3 are the most effective panel of markers in distinguishing hepatocellular carcinoma from metastatic tumor on fine-needle aspiration specimens. American journal of clinical pathology. 2012; 138: 203-10.

84. Abdelgawad IA, Mossallam GI, Radwan NH, Elzawahry HM, Elhifnawy NM. Can Glypican3 be diagnostic for early hepatocellular carcinoma among Egyptian patients? Asian Pacific journal of cancer prevention : APJCP. 2013; 14: 7345-9.

85. Yang SL, Fang X, Huang ZZ, Liu XJ, Xiong ZF, Liu P, et al. Can serum glypican-3 be a biomarker for effective diagnosis of hepatocellular carcinoma? A meta-analysis of the literature. Disease markers. 2014; 2014: 127831.

86. Shirakawa H, Suzuki H, Shimomura M, Kojima M, Gotohda N, Takahashi S, et al. Glypican-3 expression is correlated with poor prognosis in hepatocellular carcinoma. Cancer science. 2009; 100: 1403-7.

87. Cui X, Li Z, Gao PJ, Gao J, Zhu JY. Prognostic value of glypican-3 in patients with HBV-associated hepatocellular carcinoma after liver transplantation. Hepatobiliary \& pancreatic diseases international : HBPD INT. 2015; 14: 157-63.

88. Xiong XL, Qin H, Yan SQ, Zhou LS, Chen P, Zhao D. Expression of glypican-3 is highly associated with pediatric hepatoblastoma: a systemic analysis. Asian Pacific journal of cancer prevention : APJCP. 2015; 16: 1029-31.

89. Aviel-Ronen S, Lau SK, Pintilie M, Lau D, Liu N, Tsao MS, et al. Glypican-3 is overexpressed in lung squamous cell carcinoma, but not in adenocarcinoma. Modern pathology : an official journal of the United States and Canadian Academy of Pathology, Inc. 2008; 21: 817-25.

90. Lin Q, Xiong LW, Pan XF, Gen JF, Bao GL, Sha HF, et al. Expression of GPC3 protein and its significance in lung squamous cell carcinoma. Medical oncology. 2012; 29: 663-9

91. Yu X, Li Y, Chen SW, Shi Y, Xu F. Differential expression of glypican-3 (GPC3) in lung squamous cell carcinoma and lung adenocarcinoma and its clinical significance. Genetics and molecular research : GMR. 2015; 14: 10185-92.

92. Nakatsura T, Kageshita T, Ito S, Wakamatsu K, Monji M, Ikuta Y, et al. Identification of glypican-3 as a novel tumor marker for melanoma. Clinical cancer research : an official journal of the American Association for Cancer Research. 2004; 10: 6612-21.

93. Ikuta Y, Nakatsura T, Kageshita T, Fukushima S, Ito S, Wakamatsu K, et al. Highly sensitive detection of melanoma at an early stage based on the increased serum secreted protein acidic and rich in cysteine and glypican-3 levels. Clinical cancer research : an official journal of the American Association for Cancer Research. 2005; 11: 8079-88.

94. Kandil D, Leiman G, Allegretta M, Evans M. Glypican-3 protein expression in primary and metastatic melanoma: a combined immunohistochemistry and immunocytochemistry study. Cancer. 2009; 117: 271-8.

95. Aydin O, Yildiz L, Baris S, Dundar C, Karagoz F. Expression of Glypican 3 in low and high grade urothelial carcinomas. Diagnostic pathology. 2015; 10: 34

96. Ishiguro T, Sugimoto M, Kinoshita Y, Miyazaki Y, Nakano K, Tsunoda H, et al. Anti-glypican 3 antibody as a potential antitumor agent for human liver cancer. Cancer research. 2008; 68: 9832-8.

97. Nakano K, Orita T, Nezu J, Yoshino T, Ohizumi I, Sugimoto M, et al. Anti-glypican 3 antibodies cause ADCC against human hepatocellular carcinoma cells. Biochemical and biophysical research communications. 2009; 378: $279-84$

98. Ikeda M, Ohkawa S, Okusaka T, Mitsunaga S, Kobayashi S, Morizane C, et al. Japanese phase I study of GC33, a humanized antibody against glypican-3 for advanced hepatocellular carcinoma. Cancer science. 2014; 105: 455-62.

99. Zhu AX, Gold PJ, El-Khoueiry AB, Abrams TA, Morikawa H, Ohishi N, et al. First-in-man phase I study of GC33, a novel recombinant humanized antibody against glypican-3, in patients with advanced hepatocellular carcinoma. Clinical cancer research : an official journal of the American Association for Cancer Research. 2013; 19: 920-8.

100. Abou-Alfa GK, Puig O, Daniele B, Kudo M, Merle P, Park JW, et al. Randomized phase II placebo controlled study of codrituzumab in previously treated patients with advanced hepatocellular carcinoma. Journal of hepatology. 2016; 65: 289-95.

101. Ishiguro T, Sano Y, Komatsu SI, Kamata-Sakurai M, Kaneko A, Kinoshita Y, et al. An anti-glypican 3/CD3 bispecific T cell-redirecting antibody for treatment of solid tumors. Science translational medicine. 2017; 9

102. Zhang YF, Ho M. Humanization of high-affinity antibodies targeting glypican-3 in hepatocellular carcinoma. Scientific reports. 2016; 6: 33878 .
103. Feng M, Gao W, Wang R, Chen W, Man YG, Figg WD, et al. Therapeutically targeting glypican-3 via a conformation-specific single-domain antibody in hepatocellular carcinoma. Proceedings of the National Academy of Sciences of the United States of America. 2013; 110: E1083-91.

104. Thomas A, Teicher BA, Hassan R. Antibody-drug conjugates for cancer therapy. The Lancet Oncology. 2016; 17: e254-e62.

105. Fu Y, Urban DJ, Nani RR, Zhang YF, Li N, Fu H, et al. Glypican-3 Specific Antibody Drug Conjugates Targeting Hepatocellular Carcinoma. Hepatology. 2018.

106. Mazor R, Onda M, Pastan I. Immunogenicity of therapeutic recombinant immunotoxins. Immunological reviews. 2016; 270: 152-64.

107. Fleming BD, Ho M. Glypican-3 Targeting Immunotoxins for the Treatment of Liver Cancer. Toxins. 2016; 8.

108. Gao W, Tang Z, Zhang YF, Feng M, Qian M, Dimitrov DS, et al. Immunotoxin targeting glypican-3 regresses liver cancer via dual inhibition of Wnt signalling and protein synthesis. Nature communications. 2015; 6: 6536.

109. Wang C, Gao W, Feng M, Pastan I, Ho M. Construction of an immunotoxin, HN3-mPE24, targeting glypican-3 for liver cancer therapy. Oncotarget. 2017; 8: 32450-60.

110. Mitsunaga M, Ogawa M, Kosaka N, Rosenblum LT, Choyke PL, Kobayashi H. Cancer cell-selective in vivo near infrared photoimmunotherapy targeting specific membrane molecules. Nature medicine. 2011; 17: 1685-91.

111. Hanaoka H, Nagaya T, Sato K, Nakamura Y, Watanabe R, Harada T, et al. Glypican-3 targeted human heavy chain antibody as a drug carrier for hepatocellular carcinoma therapy. Molecular pharmaceutics. 2015; 12: 2151-7.

112. Hanaoka H, Nakajima T, Sato K, Watanabe R, Phung Y, Gao W, et al. Photoimmunotherapy of hepatocellular carcinoma-targeting Glypican-3 combined with nanosized albumin-bound paclitaxel. Nanomedicine. 2015; 10: 1139-47.

113. June $\mathrm{CH}$, Sadelain M. Chimeric Antigen Receptor Therapy. The New England journal of medicine. 2018; 379: 64-73.

114. Gao H, Li K, Tu H, Pan X, Jiang H, Shi B, et al. Development of T cells redirected to glypican-3 for the treatment of hepatocellular carcinoma. Clinical cancer research : an official journal of the American Association for Cancer Research. 2014; 20: 6418-28.

115. Shimizu Y, Suzuki T, Yoshikawa T, Tsuchiya N, Sawada Y, Endo I, et al. Cancer immunotherapy-targeted glypican-3 or neoantigens. Cancer science. 2018; 109: 531-41.

116. Jiang Z, Jiang X, Chen S, Lai Y, Wei X, Li B, et al. Anti-GPC3-CAR T Cells Suppress the Growth of Tumor Cells in Patient-Derived Xenografts of Hepatocellular Carcinoma. Frontiers in immunology. 2016; 7: 690.

117. Chen C, Li K, Jiang H, Song F, Gao H, Pan X, et al. Development of T cells carrying two complementary chimeric antigen receptors against glypican-3 and asialoglycoprotein receptor 1 for the treatment of hepatocellular carcinoma. Cancer immunology, immunotherapy : CII. 2017; 66: 475-89.

118. Pan Z, Di S, Shi B, Jiang H, Shi Z, Liu Y, et al. Increased antitumor activities of glypican-3-specific chimeric antigen receptor-modified T cells by coexpression of a soluble PD1-CH3 fusion protein. Cancer immunology, immunotherapy : CII. 2018; 67: 1621-34.

119. Guo X, Jiang H, Shi B, Zhou M, Zhang H, Shi Z, et al. Disruption of PD-1 Enhanced the Anti-tumor Activity of Chimeric Antigen Receptor T Cells Against Hepatocellular Carcinoma. Frontiers in pharmacology. 2018; 9: 1118.

120. Zhao R, Cheng L, Jiang Z, Wei X, Li B, Wu Q, et al. DNAX-activating protein 10 co-stimulation enhances the anti-tumor efficacy of chimeric antigen receptor T cells. Oncoimmunology. 2019; 8: e1509173.

121. Wang WN, Zhou GY, Zhang WL. NK-92 cell, another ideal carrier for chimeric antigen receptor. Immunotherapy. 2017; 9: 753-65.

122. Yu M, Luo H, Fan M, Wu X, Shi B, Di S, et al. Development of GPC3-Specific Chimeric Antigen Receptor-Engineered Natural Killer Cells for the Treatment of Hepatocellular Carcinoma. Molecular therapy : the journal of the American Society of Gene Therapy. 2018; 26: 366-78.

123. Li N, Fu H, Hewitt SM, Dimitrov DS, Ho M. Therapeutically targeting glypican-2 via single-domain antibody-based chimeric antigen receptors and immunotoxins in neuroblastoma. Proceedings of the National Academy of Sciences of the United States of America. 2017; 114: E6623-E31.

124. Nakatsura T, Komori H, Kubo T, Yoshitake Y, Senju S, Katagiri T, et al. Mouse homologue of a novel human oncofetal antigen, glypican-3, evokes T-cell-mediated tumor rejection without autoimmune reactions in mice. Clinical cancer research : an official journal of the American Association for Cancer Research. 2004; 10: 8630-40.

125. Komori H, Nakatsura T, Senju S, Yoshitake Y, Motomura Y, Ikuta Y, et al. Identification of HLA-A2- or HLA-A24-restricted CTL epitopes possibly useful for glypican-3-specific immunotherapy of hepatocellular carcinoma. Clinical cancer research : an official journal of the American Association for Cancer Research. 2006; 12: 2689-97.

126. Sawada Y, Sakai M, Yoshikawa T, Ofuji K, Nakatsura T. A glypican-3-derived peptide vaccine against hepatocellular carcinoma. Oncoimmunology. 2012; 1 : 1448-50.

127. Sawada $Y$, Yoshikawa $T$, Nobuoka $D$, Shirakawa $H$, Kuronuma $T$, Motomura $Y$, et al. Phase I trial of a glypican-3-derived peptide vaccine for advanced hepatocellular carcinoma: immunologic evidence and potential for improving overall survival. Clinical cancer research : an official journal of the American Association for Cancer Research. 2012; 18: 3686-96.

128. Sawada Y, Yoshikawa T, Fujii S, Mitsunaga S, Nobuoka D, Mizuno S, et al. Remarkable tumor lysis in a hepatocellular carcinoma patient immediately 
following glypican-3-derived peptide vaccination: an autopsy case. Human vaccines \& immunotherapeutics. 2013; 9: 1228-33.

129. Suzuki S, Shibata K, Kikkawa F, Nakatsura T. Significant clinical response of progressive recurrent ovarian clear cell carcinoma to glypican-3-derived peptide vaccine therapy: two case reports. Human vaccines \& immunotherapeutics. 2014; 10: 338-43.

130. Sawada Y, Yoshikawa T, Ofuji K, Yoshimura M, Tsuchiya N, Takahashi M, et al. Phase II study of the GPC3-derived peptide vaccine as an adjuvant therapy for hepatocellular carcinoma patients. Oncoimmunology. 2016; 5: e1129483. 